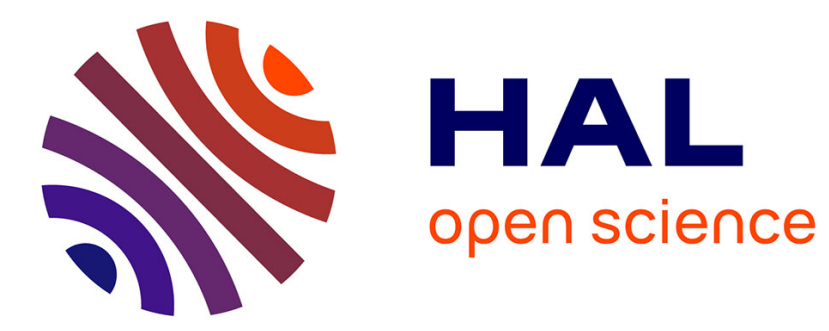

\title{
Current-mirror based PID controller
}

Vratislav Michal, Christophe Premont, Gaël Pillonnet, Nacer Abouchi

\section{To cite this version:}

Vratislav Michal, Christophe Premont, Gaël Pillonnet, Nacer Abouchi. Current-mirror based PID controller. International New Circuits and Systems Conference, IEEE, 2011, Bordeaux, France. pp.4, 10.1109/NEWCAS.2011.5981312 . hal-01103654

\section{HAL Id: hal-01103654 https://hal.science/hal-01103654}

Submitted on 15 Jan 2015

HAL is a multi-disciplinary open access archive for the deposit and dissemination of scientific research documents, whether they are published or not. The documents may come from teaching and research institutions in France or abroad, or from public or private research centers.
L'archive ouverte pluridisciplinaire HAL, est destinée au dépôt et à la diffusion de documents scientifiques de niveau recherche, publiés ou non, émanant des établissements d'enseignement et de recherche français ou étrangers, des laboratoires publics ou privés. 


\title{
Current-Mirror Based PID Controller
}

\author{
Vratislav Michal ${ }^{1,2}$, Christophe Premont ${ }^{2}$, Gael Pillonnet ${ }^{1}$ and Nacer Abouchi ${ }^{1}$ \\ 1) CPE-Lyon, 43 boulevard du 11 Novembre 1918, Villeurbanne, France \\ ${ }^{2)}$ ST-Ericsson, 12 rue Jules Horowitz, Grenoble, France
}

\begin{abstract}
ProportionalIntegration-Derivative (PID) controller, based on the currentdifference amplifier, is presented. This architecture allows to integrate the controller, employing only four active MOS transistors. It also allows obtaining interesting features, such as the low power-consumption, and high bandwidth, in spite of the low DC accuracy. In this paper, design equations for the DC operation point setting, transfer function, and the MOS transistor sizing are provided. The performances are demonstrated by a simulation of the circuit designed in $40 \mathrm{~nm}$ CMOS, employed to stabilize the feedback-loop of switched DC/DC buck converter.
\end{abstract}

\section{INTRODUCTION}

In the design of continuous-time PID-like controllers, various structures based on the active elements can be used. For instance, [1] presents the overview of the voltage mode (voltage input/output) PID controllers, based on the operation amplifier, OTA, and CCII. Alternatively, current mode controllers recently emerged in literature, based e.g. on the CCII, CDTA or grounded synthetic inductance (see [2 - 4] for instance). The common factors of merit of a controller are the power-consumption, frequency bandwidth, offset, and DC gain.

In this paper, the circuit reaching interesting power consumption vs. frequency bandwidth trade-off is presented. The structure is based on the current-difference amplifier (CDA) which can be implemented by only two simple current mirrors [2]. The circuit does not require the frequency compensation, which allows to extend the frequency bandwidth. This might be advantageous compared to the operation amplifier based counterparts [1]. On the contrary, the structure exhibits inherently higher DC offset, due to the lower current mirrors accuracy (mismatch). On this account, the controller is intended mainly for devices requiring a highquality (fast) regulation, while admitting a DC offset in the order of tens of milivolts. Developed application concerns the power-supply chain of the audio and RF power amplifiers.

This article is organized in four parts. In section II, the concept of controller based on the ideal CDA is presented. In section III, the AC and DC analyses of the current-mirror based PID controller are provided. Section IV relates the transistor sizing to the DC controller gain, and the last section provides an example of the controller designed in $40 \mathrm{~nm}$ CMOS, applied to the switching step-down DC/DC converter.

The work and results reported here were obtained with research funding from ST-Ericsson and French government research program in microelectronic and nanotechnologies Nano-2012.

\section{BASIC CONCEPT OF THE CONTROLLER}

The current-difference amplifier CDA provides the difference of input currents $I_{1}$ and $I_{2}$ in such a way that $I_{\mathrm{OUT}}=F\left(I_{1}-I_{2}\right)$, where $F$ is usually set to unity. However, while using the CDA as the voltage-mode PID controller, the conversion of the input/output voltages to the currents with appropriate dynamics (PID) is required. This can be obtained by the circuit shown in Fig. 1, where the input (reference) and feedback currents $I_{\mathrm{REF}}$ and $I_{\mathrm{FB}}$ are generated by means of $R_{\mathrm{REF}}$ and $Z_{1}$. The output voltage occurs across the impedance $Z_{2}$.

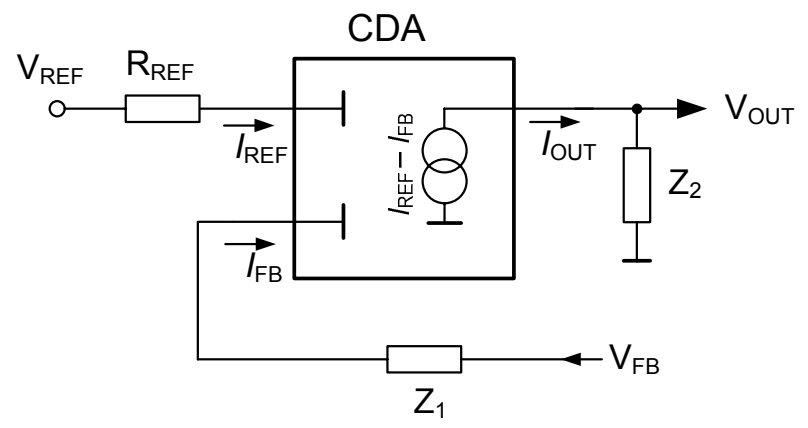

Figure 1. Idealized schematics of the controller.

The values of reference and feedback currents $I_{\mathrm{REF}}$ and $I_{\mathrm{FB}}$ in Fig. 1 controller circuit can be expressed as:

$$
I_{R E F}=\frac{V_{R E F}}{R_{R E F}} \quad \text { and } \quad I_{F B}=\frac{V_{F B}}{Z_{1}}
$$

where $V_{\mathrm{FB}}$ refers to the regulated (feedback) voltage. Since the output current results from the current difference $I_{\mathrm{REF}}-I_{\mathrm{FB}}$, the output voltage of the controller can be revealed as:

$$
V_{\text {OUT }}=\left(I_{R E F}-I_{F B}\right) \cdot Z_{2}=\left(\frac{V_{R E F}}{R_{R E F}}-\frac{V_{F B}}{Z_{1}}\right) \cdot Z_{2}
$$

We can therefore express the condition of steady-state regulation:

$$
I_{\text {REF }}-I_{F B}=0
$$

The manner to design the impedances $Z_{1}, Z_{2}$ then allows to attain the control regulation condition with the appropriate dynamics of the controller: PD, PI, PID or derivative filtered PID, see $[1,3]$. 


\section{Current-Mirror BASEd Controller}

The circuit representing the controller based on twocurrent mirrors CDA [2] is shown in Fig. 2. Compared to Fig. 1, the CDA from Fig. 2 has to be considered as non-ideal, due to the nonzero input impedances $1 / \mathrm{g}_{\mathrm{m}}$ and $1 / \mathrm{g}_{\mathrm{m}}$ of the current inputs.

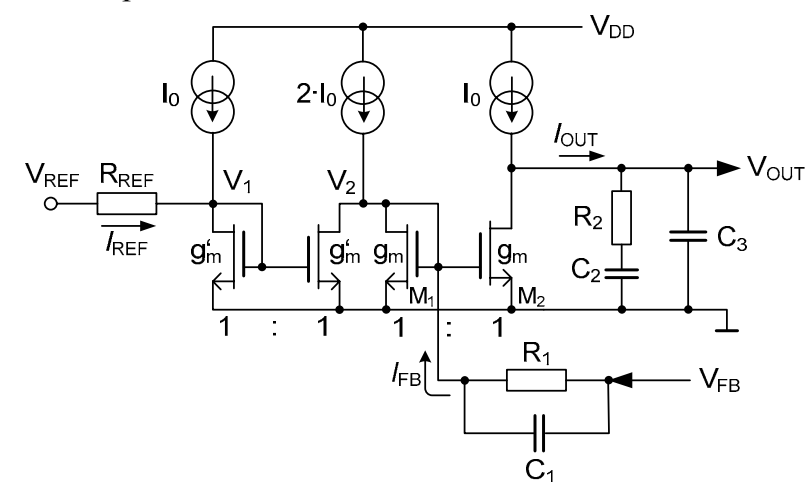

Figure 2. PID (type-3) controller based on two-current mirrors CDA. In the following, we consider all transistor W/Ls identicall.

In this idealized schematic, we distinguish two mentioned current mirrors, reference current source resistance $R_{\mathrm{REF}}+g_{\mathrm{m}}$ impedance $Z_{1}$ containing $R_{1}, C_{1}, g_{\mathrm{m}}$, and impedance $Z_{2}$ composed of $R_{2}, C_{2}$, and $C_{3}$. The current sources are designed in order to provide the zero output current $I_{\mathrm{OUT}}$ in the steadystate (3).

\section{A. Transfer Function, Components Values}

The transfer function of the PID controller can be expressed e.g. in the general zero-pole form [1]:

$$
C(s)=K \frac{\left(s / z_{1}+1\right)\left(s / z_{2}+1\right)}{s \cdot\left(s / p_{1}+1\right)\left(s / p_{2}+1\right)}
$$

where $z_{\mathrm{n}}$ refers to the real controller zeros, and $p_{\mathrm{n}}$ to the real pole frequencies (all in $\mathrm{rad} / \mathrm{s}$ ). An alternative type of controller (PI, PID, and derivative filtered PID) can be obtained by the appropriate selection of $z_{\mathrm{n}}$ and $p_{\mathrm{n}}$ (see [1], [3] for more details).

The small-signal analysis of the circuit shown in Fig. 2 reveals the transfer function $V_{\mathrm{OUT}} / V_{\mathrm{FB}}$ in the following zero pole form:

$$
\frac{V_{\text {OUT }}}{V_{F B}}=\frac{-g_{m}\left(1+s C_{2} R_{2}\right)\left(1+s C_{1} \cdot R_{1}\right)}{s \cdot\left(1+R_{1} g_{m}\right)\left(C_{2}+C_{3}\right)\left(1+s R_{2} \frac{C_{2} C_{3}}{C_{2}+C_{3}}\right)\left(1+s \frac{C_{1} R_{1}}{R_{1} g_{m}+1}\right)}
$$

where $g_{\mathrm{m}}$ is the transconductance of transistor $\mathrm{M}_{1}$ :

$$
g_{m(M 1)}=\sqrt{2 K P(W / L) I_{0}}
$$

The values of the passive components from Fig. 2 circuit can be found by solving the set of linear equations obtained by comparing the coefficients of transfer functions (4) and (5):

$$
\begin{array}{ccc}
R_{1}=r_{1} & R_{2}=\frac{K R_{1} p_{1} p_{2}}{z_{2}\left(p_{1}-z_{1}\right)\left(p_{2}-z_{2}\right)} & C_{3}=\frac{z_{2}\left(p_{1}-z_{1}\right)}{K R_{1} p_{1} p_{2}} \\
C_{1}=\frac{1}{z_{1} R_{1}} & C_{2}=\frac{\left(p_{1}-z_{1}\right)\left(p_{2}-z_{2}\right)}{K R_{1} p_{1} p_{2}} & g_{m}=\frac{p_{1}-z_{1}}{z_{1} R_{1}}
\end{array}
$$

where $r_{1}$ is an arbitrary selected value related to the impedance level. In this choice of $r_{1}$, we focus namely on the:

- value of $I_{\mathrm{REF}}$ : minimize, in order to reduce the current from

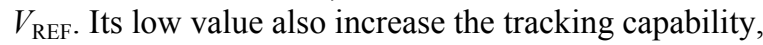

- minimization of $g_{\mathrm{m}}$ (results from (7) and is related to the transistor size and power consumption, see $E q$. (6))

- realistic value of $C_{3}$.

Notice: As for an controller PID based on the OTA [1], the transfer function $V_{\mathrm{OUT}} / V_{\mathrm{REF}}$ differs from (5):

$$
\frac{V_{O U T}}{V_{R E F}}=\frac{g_{m}\left(C_{2} R_{2} s+1\right)}{s\left(s R_{2} \frac{C_{2} C_{3}}{C_{2}+C_{3}}+1\right)\left(C_{2}+C_{3}\right)\left(1+R_{R E F} g_{m}\right)}
$$

The transfer function (8) has to be considered in some specific regulation schemes, namely when the fast tracking capabilities are required by the system.

\section{B. DC Transfer Function}

The value of $R_{\mathrm{REF}}$ can be found by applying the steadystate regulation condition $I_{\mathrm{REF}}=I_{\mathrm{FB}}(3)$. Due to the nonconstant tracking gain $V_{\mathrm{FB}} / V_{\mathrm{REF}}, R_{\mathrm{REF}}$ is to be determined for each single reference voltage $V_{\mathrm{REF}}$. In practice, $R_{\mathrm{REF}}$ can be found by the iterative DC simulation. In this paragraph, we point to the complicated, but closely linear relationship between $R_{\mathrm{REF}}$ and tracking gain $V_{\mathrm{FB}} / V_{\mathrm{REF}}$. In order to determine the steady-state currents $I_{\mathrm{REF}}$ and $I_{\mathrm{FB}}$, we refer to the $1^{\text {st }}$ order quadratic equation of an MOS [2]:

$$
I_{D}=\frac{\beta}{2}\left(V_{G S}-\left|V_{T H}\right|\right)^{2}
$$

where $I_{D}$ is the drain current, $\beta=K P \cdot W / L$ is the transistor gain, $V_{\mathrm{TH}}$ the threshold voltage, and $V_{\mathrm{GS}}$ the gate-to-source voltage. Condition $I_{\mathrm{REF}}=I_{\mathrm{FB}}$ can be then expressed in terms circuits' components values of Fig. 2:

$$
\frac{V_{R E F}-V_{1}}{R_{R E F}}=\frac{V_{F B}-V_{2}}{R_{1}}
$$

As the steady-state drain current of $\mathrm{M}_{1}$ is $I_{0}$, the nodal voltages $V_{1}$ and $V_{2}$ result from (9):

$$
V_{1}=\sqrt{\frac{2\left(I_{R E F}+I_{0}\right)}{\beta}}+V_{T H} ; \quad V_{2}=\sqrt{\frac{2 I_{0}}{\beta}}+V_{T H}
$$

and the value of current $I_{\mathrm{REF}}$ results from (11) as:

$$
I_{R E F}=\frac{1}{R_{1}}\left(V_{F B}-\sqrt{\frac{2 I_{0}}{\beta}}-V_{T H}\right)
$$

These equations yield the following value of $R_{\mathrm{REF}}$ :

$$
R_{R E F}=\frac{R_{1} \sqrt{\frac{\beta}{2}}\left(V_{T H}-V_{R E F}\right)+\sqrt{R_{1}\left(V_{F B}-V_{T H}-\sqrt{\frac{2 I_{0}}{\beta}}+I_{0} R_{1}\right)}}{\sqrt{\frac{\beta}{2}}\left(V_{T H}-V_{F B}\right)+\sqrt{I_{0}}}
$$

From this equation, the nonlinear tracking gain $V_{\mathrm{FB}} / V_{\mathrm{REF}}$ can be evaluated. A curve presenting the example of the tracking gain of the controller presented in section $V$ is shown in Fig. 3 . 


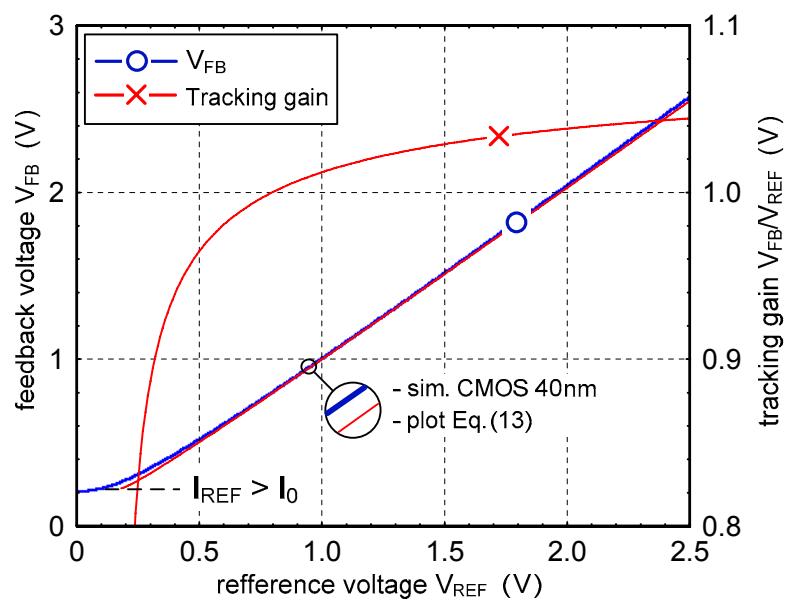

Figure 3. Simulated and calculated tracking characteristic and tracking gain, provided on the design example from section $V$.

\section{DC GAIN AND TRANSISTOR SIZING}

In reality, the ideal infinite gain of the controller $G_{\mathrm{DC}}$ is reduced by the drain conductances of $\mathrm{M}_{2}$ and $I_{0}$ current sources $g_{\mathrm{dso}}$ and $g_{\mathrm{dso}, \mathrm{P}}$. This maximal gain is comparable e.g. to OTA controller PID, being in order of $40 \mathrm{~dB}$. The value of the controller gain is related to the regulation accuracy of the closed loop [3] (see section V).

In order to evaluate the value of $G_{\mathrm{DC}}$, we can build the small signal scheme of the controller shown in Fig. 4.

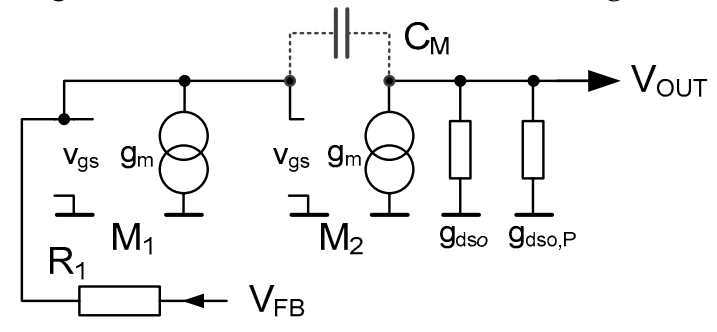

Figure 4. Simplified small signal model of the controller.

The analysis of the linearised circuit allows to obtain the value of $G_{\mathrm{DC}}$ as the function of $g_{\mathrm{m}}$ and $g_{\mathrm{dso}}$ :

$$
G_{D C}=\frac{\partial V_{\text {OUT }}}{\partial V_{F B}}=\frac{-g_{m}}{\left(g_{d s o}+g_{d s o, P}\right)\left(R_{1} g_{m}+1\right)}
$$

where $\mathrm{g}_{\mathrm{dso}} \approx \lambda_{0} \mathrm{I}_{0} /\left(L \cdot V_{\mathrm{DS}}\right) \quad\left(\lambda_{0}\right.$ refers to the channel length modulation of the output transistors, [2]). The (14) can be rewritten in terms of the parameters of the transistor (we neglect the influence of the current source conductance $g_{\text {dso,p: }}$ :

$$
G_{D C}=-\frac{\sqrt{2 K P_{N} \frac{W}{L}}}{\frac{\lambda_{0 n} \sqrt{I_{D}}}{V_{\text {OUT }} L}\left(R_{1} \sqrt{2 K P_{N} \frac{W}{L} I_{0}}+1\right)}
$$

This expression can be used to evaluate the trade-off between $G_{\mathrm{DC}}, L_{(\mathrm{M} 1)}$, and $I_{0}$. Example of this dependency is plotted in Fig. 5 (see also example in section V).

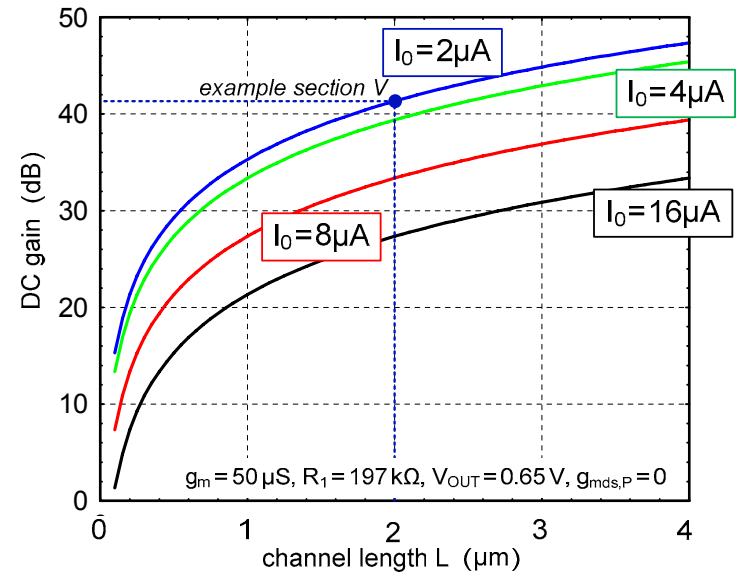

Figure 5. Impact of $I_{0}$ and transistor channel scaling to DC gain.

From this figure, we notice the impact of the bias current $I_{0}$ on the $G_{\mathrm{DC}}$. The lowest value of $I_{0}$ is limited by the required transistor operating regime (saturation), and also has an important impact to the maximal frequency bandwidth as well as the positive slew-rate of the controller.

\section{Design EXAMPLE}

Performances of the circuit are demonstrated by the example of design in $40 \mathrm{~nm}$ CMOS $(2.5 \mathrm{~V})$. The design aims to stabilize the feedback loop of the switched-mode step-down (buck) DC/DC converter. In the $1^{\text {st }}$ order approximation, the step-down DC/DC converter can be modeled as the linear dynamic system, composed of the controller, LC filter, and constant gain $G$, shared between PWM modulator and output stage (see block scheme in [4]). For our design example, we consider the following parameters of the converter: $L=0.47 \mu \mathrm{H}, C=10 \mu \mathrm{F}, R_{\mathrm{L}}=150 \mathrm{~m} \Omega, R_{\mathrm{ESR}}=20 \mathrm{~m} \Omega, G=4$ and we require the operating point $V_{\mathrm{REF}}=V_{\mathrm{FB}}=1 \mathrm{~V}$. The process parameters for the design were obtained by the least-squares approximation of the transistor $\mathrm{I} / \mathrm{V}$ characteristics [8] as: $\mathrm{KP}_{\mathrm{N}}=134 \mu \mathrm{V} / \mathrm{A}^{2}, \mathrm{~V}_{\mathrm{THN}}=0.542 \mathrm{~V}$ and $\lambda_{0 \mathrm{n}}=32 \mathrm{mV} \cdot \mu \mathrm{m}^{-1}$.

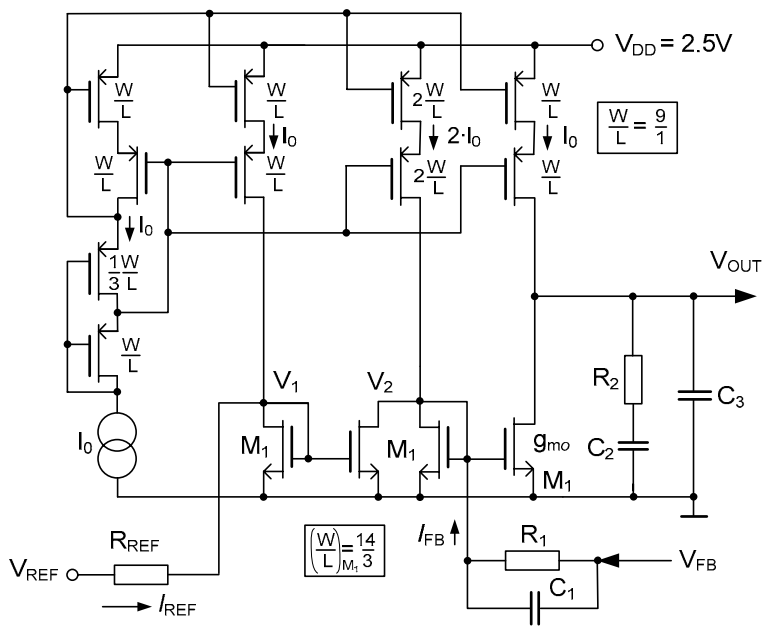

Figure 6. Schematic diagram of the controller using the high-voltage swing cascade [9] allowing to increase DC gain and voltage dynamic range. 


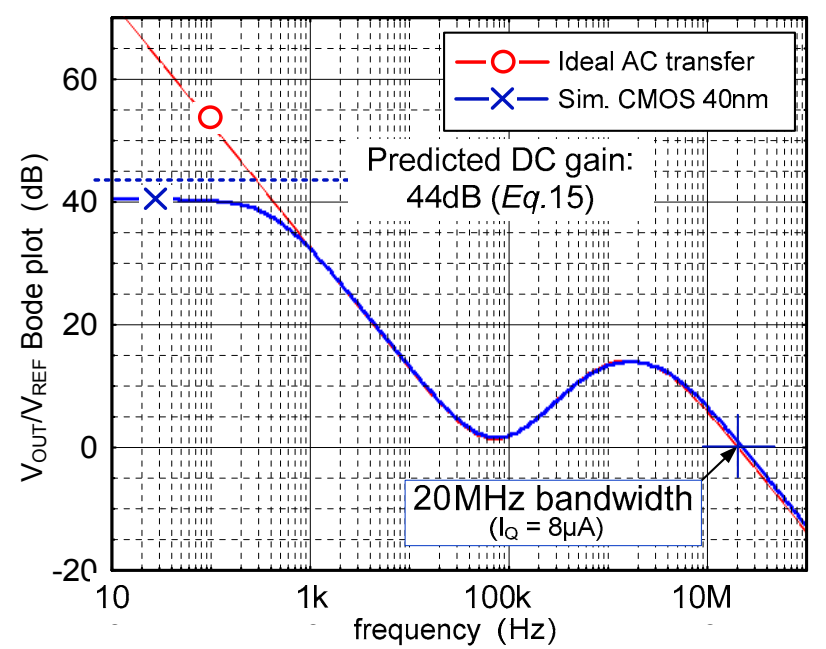

Figure 7. Ideal and simulated frequency characteristic (CMOS 40nm).

The transfer function of the controller was obtained using the procedure from [7], requiring peak of the load transient response of $55 \mathrm{mV}$ per ampere of load current step, and bandwidth of $20 \mathrm{MHz}$. The transfer function can be expressed in the pole-zero form (4) as:

$$
C(s)=\underset{\text { gain } G}{\frac{1}{4}} \frac{2.67 \cdot 10^{6}\left(s / 4.61 \cdot 10^{5}+1\right)\left(s / 4.61 \cdot 10^{5}+1\right)}{s\left(s / 2.05 \cdot 10^{7}+1\right)\left(s / 5 \cdot 10^{6}+1\right)}
$$

which, by using (7) allows to obtain a set of component values: $R_{1}=197 \mathrm{k} \Omega, R_{2}=128 \mathrm{k} \Omega, C_{1}=11 \mathrm{pF}, C_{2}=16.9 \mathrm{pF}$, $C_{3}=0.39 \mathrm{pF}, g_{\mathrm{m}}=50 \mu \mathrm{S}$. From Fig. 5 , we select the transistor parameters $I_{0}=2 \mu \mathrm{A}$, and $L=3 \mu \mathrm{m}$, which allows to estimate the controller gain $G_{\mathrm{DC}}=43 \mathrm{~dB}\left(V_{\mathrm{OUT}}\right.$ in $\left.(15)=0.65 \mathrm{~V}\right)$. The corresponding transistor width results from (6) as $W=14 \mu \mathrm{m}$ $\left(g_{\mathrm{m}}=50 \mu \mathrm{S}\right)$. The value of $R_{\mathrm{REF}}$ is computed from (13) as $180.1 \mathrm{k} \Omega$, and can be adjusted by the accurate DC simulation (computed voltage $V_{\mathrm{FB}}$ is shifted by $9 \mathrm{mV}$ ). The main circuit of the controller is shown in Fig. 6. Here, we make use of the high voltage swing Sooch cascode [9] for reducing the impact of $g_{\text {dso.P }}$ in (14) and obtaining high $V_{\text {OUT }}$ dynamics.

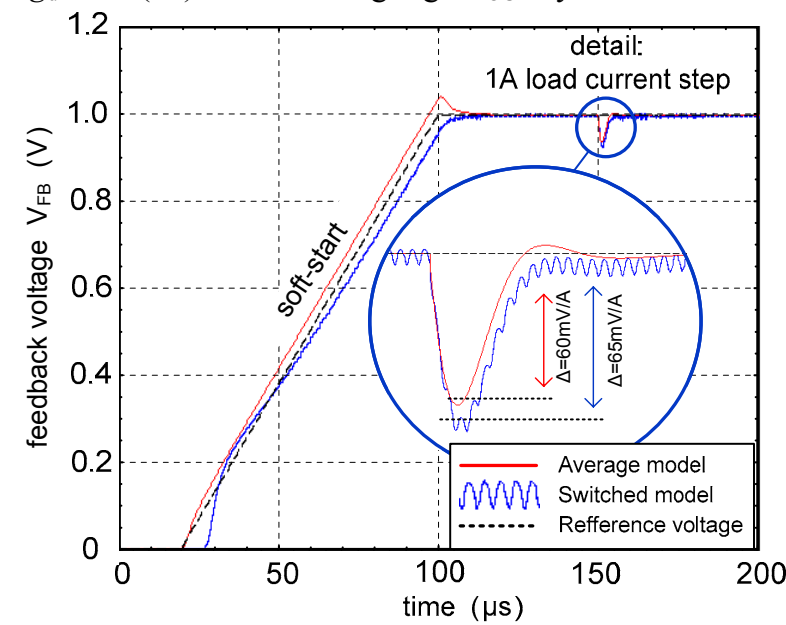

Figure 8. Transient analysis of the buck converter provided by the ideal (average), and complex (real) switched model of the converter.
The simulated AC characteristic of the controller shown in Fig. 7 corresponds with reference transfer function (16). Obtained DC gain $41 \mathrm{~dB}$ causes the steady-state regulation error lower than $1 \mathrm{mV}$ per ampere of load current. As shown in Fig. 8, this controller allows to provide the transient response undershoot of the buck DC/DC converter, which is close to the required value $55 \mathrm{mV} / \mathrm{A}$.

As previously mentioned, the controller exhibits nonnegligible DC offset due to the transistor mismatch. This effect is demonstrated by the Monte-Carlo simulation of the output voltage $\left(V_{\mathrm{FB}}\right)$ dispersion, shown in Fig. 9. The obtained dispersion is in order of $\pm 30 \mathrm{mV}$ and would require a postfabrication trimming or the additional circuit calibration.

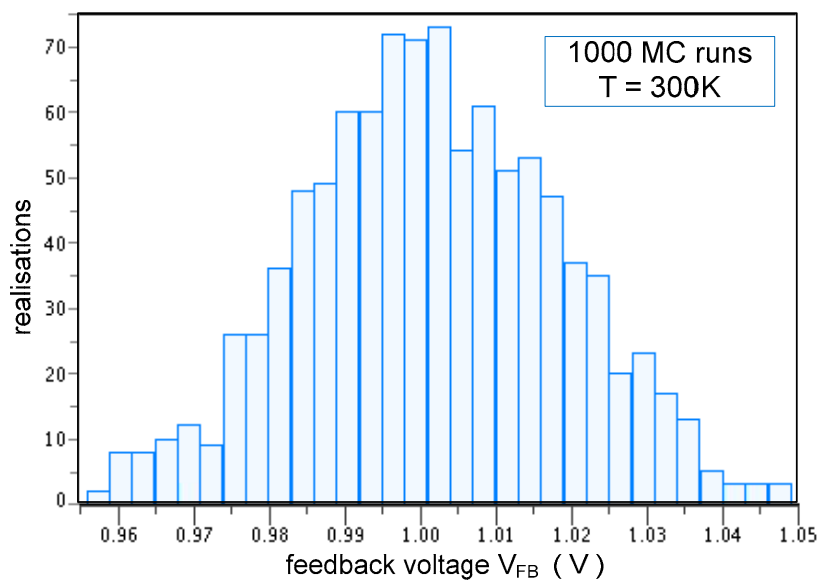

Figure 9. Monte-Carlo simulation of the output voltage $V_{\text {OUT }}$ dispersion.

\section{CONCLUSION}

In this paper, PID controller circuit was presented, based on the current-difference amplifier. It was shown that the presented circuit allows to obtain interesting frequency range vs. power consumption trade-off. The detailed design equations and analysis of the circuit was presented and demonstrated on the designed circuits, where $20 \mathrm{MHz}$ of the frequency bandwidth was obtained with only $8 \mu \mathrm{A}$ of the static bias current.

\section{REFERENCES}

[1] V. Michal, C. Premont, G. Pillonnet, N. Abouchi, "Single-active element PIC controller", $20^{\text {th }}$ IEEE conference Radioelektronika 2010, Brno - Czech Republic.

[2] J.B. Baker, "CMOS Circuit Design, Layout, and Simulation, WileyIEEE Press 1997.

[3] A. Dwyer, "Handbook of PI and PID controller tuning rules". Book, Imperial College Press, 2006.

[4] V. Michal et al. "Zero-derivative method of analog controller design applied to step-down DC-DC converters". IEEE ISCAS, Paris 2010.

[5] S. Minaei, E. Yuce, S. Tokat, O. Cicekoglu, "Simple realization of current-mode and voltage mode PID, PI and PD controllers". Proceeding IEEE of ISIE, 2005.

[6] A. U. Kesin, "Design of a PID controller circuit employing CDBAs", Int. J. of Electrical Engineering Education, Vol. 43. No. 1 (2006).

[7] V. Michal, "Arbitrarily overshoot method of the controller design for the switched step-down DC/DC converters", paper in preparation.

[8] V. Michal, Ph.D. Thesis, available at http://tel.archives-ouvertes.fr/

[9] N.S. Sooch, "MOS Cascode Current Mirror". U.S. Patent No 4550284. 